\title{
Gastrointestinal haemorrhage in extracorporeal membrane oxygenation: insights from the national inpatient sample
}

\author{
Shantanu Solanki ${ }^{1}$, Khwaja Fahad Haq ${ }^{2}$, George Jolly ${ }^{3}$, Raja Chandra Chakinala ${ }^{1}$, \\ Muhammad Ali Khan ${ }^{4}$, Neil R. Patel ${ }^{5}$, Abhishek Bhurwal ${ }^{6}$, Khwaja Saad Haq ${ }^{7}$, Christopher Nabors ${ }^{8}$, \\ Sarju Ganatra ${ }^{9}$, Wilbert Aronow ${ }^{10}$
}

\author{
'Department of Medicine, Geisinger Commonwealth School of Medicine, Scranton, PA, \\ United States \\ 2Division of Gastroenterology, Henry Ford Hospital, Detroit, MI, United States \\ ${ }^{3}$ Division of Cardiology, Loma Linda University Medical Center, Loma Linda, CA, United \\ States \\ ${ }^{4}$ Division of Gastroenterology, University of Alabama at Birmingham, Birmingham, AL, \\ United States \\ ${ }^{5}$ Division of Cardiology, The Wright Center for Graduate Medical Education, Scranton, PA, \\ United States \\ ${ }^{6}$ Division of Gastroenterology and Hepatology, Robert Wood Johnson University Hospital, \\ New Brunswick, NJ, United States \\ ${ }^{7}$ Department of Medicine, Kingsbrook Jewish Medical Center, Brooklyn, NY, United States \\ ${ }^{8}$ Department of Medicine, Westchester Medical Center, Valhalla, NY, United States \\ ${ }^{9}$ Division of Cardiology, Lahey Hospital and Medical Center, Burlington, MA, United States \\ ${ }^{10}$ Division of Cardiology, Westchester Medical Center, Valhalla, NY, United States
}

Submitted: 31 May 2019

Accepted: 6 September 2019

Arch Med Sci

DOI: https://doi.org/10.5114/aoms/112199

Copyright @ 2020 Termedia \& Banach

\begin{abstract}
Introduction: Extracorporeal membrane oxygenation (ECMO) is associated with gastrointestinal haemorrhage $(\mathrm{GIH})$, which may result from coagulopathy, systemic inflammation, reduced gastric perfusion, and arteriovenous malformation from non-pulsatile blood flow. Data are limited regarding the burden of this complication in the United States.

Material and methods: We analysed the National Inpatient Sample (NIS) database for the years 2007 to 2011 to identify hospitalisations in which an ECMO procedure was performed. Hospitalizations complicated by GIH in this cohort were then identified by relevant codes.

Results: Between 2007 and 2011, ECMO hospitalisations increased from 1869 to 3799 ( $p$ < 0.01). The proportion of hospitalisations complicated by GIH increased from $2.12 \%$ in 2007 to $7.46 \%$ in $2011(p<0.01)$. Gastrointestinal haemorrhage was more common in men (56.7\%) and in Caucasians (57.4\%). Common comorbidities in this population were renal failure (71\%), anaemia $(55 \%)$, and hypertension (26\%). All-cause inpatient mortality showed a numerical but nonsignificant increase from $56.7 \%$ to $61.9 \%(p=0.49)$. The average cost of care per hospitalisation with GIH associated with ECMO use increased from $\$ 132,420$ in 2007 to $\$ 215,673$ in 2011 ( $p<0.01)$.

Conclusions: Gastrointestinal haemorrhage during ECMO hospitalisations occurred in small but significantly increasing proportions. The inpatient mortality rate and costs associated with GIH were substantial and increased significantly during the study period.
\end{abstract}

Key words: hospitalisation, extracorporeal membrane oxygenation, gastrointestinal haemorrhage.
Corresponding author: Shantanu Solanki, MD, MPH Department of Medicine Geisinger Commonwealth School of Medicine 525 Pine St Scranton, PA 18510 United States E-mail: shan4788@gmail.com 


\section{Introduction}

Extracorporeal life support (ECLS) is a technique to provide temporary support to cardiac or pulmonary function by using mechanical devices [1]. Extracorporeal life support is called extracorporeal membrane oxygenation (ECMO) when used in the intensive care unit (ICU) or emergency department (ED) setting to improve oxygenation, ventilation, or cardiac output [1]. Extracorporeal membrane oxygenation is used to bypass the cardiopulmonary system in patients with acute hypoxaemic respiratory failure, cardiac arrest, and cardiogenic shock, who are refractory to conventional intervention [1-3]. It can maintain tissue oxygenation for days to weeks in patients with respiratory or cardiac failure [4]. Recent studies have shown that ECMO might be a therapeutic option in refractory septic shock, myocarditis, and severe thoracic trauma patients [5-8]. There are 2 main forms of ECMO: veno-arterial (VA) ECMO and veno-venous (VV) ECMO. In VA ECMO, the circuit is connected in parallel to the heart and lungs whereas it is connected in series in VV ECMO [9]. Thus, VA ECMO provides cardiac support to assist systemic circulation whereas VV ECMO does not. A high mortality rate is associated with the use of either type of ECMO. As per the Extracorporeal Life Support Organisation (ELSO) registry report, only $43 \%$ of the adults who received ECMO for cardiac support and $59 \%$ for respiratory support survived to discharge or transfer [10]. In a meta-analysis on the outcomes of ECMO, Zangrillo et al. noted an overall mortality of $54 \%$ at 30 days post ECMO [11]. Haemorrhage is the most frequent complication during ECMO [9]. Bleeding may occur at the cannulation site, or it may be intracerebral, intrathoracic, gastrointestinal, or retroperitoneal [12]. Gastrointestinal bleeding $(\mathrm{GIB})$ has been shown to be associated with increased mortality in ECMO patients in a number of studies [13-15]. However, epidemiological data on the outcomes and economic burden of gastrointestinal haemorrhage $(\mathrm{GIH})$ associated with ECMO hospitalisations are limited.

\section{Material and methods}

\section{Source of data}

The NIS, designed by the Agency for Healthcare Research and Quality (AHRQ), is the largest all-payer inpatient database in the U.S. Each individual hospitalisation is de-identified and maintained in the NIS as a unique entry with one primary discharge diagnosis and up to 24 secondary diagnoses during that hospitalisation. Each entry includes demographic information including race, age, primary payer, income level by zip code as well as medical comorbidities, primary/secondary procedures, hospitalisation outcomes, length of stay, and cost of care.
Data are compiled yearly and contain discharge information from over 1200 hospitals located across 45 states in the U.S. The NIS was designed to approximate a $20 \%$ stratified sample of community hospitals in the country and provides sampling weights to calculate national estimates [16] The internal validity of the database is guaranteed by annual data quality assessments of the sample. Moreover, comparisons with data sources like the American Hospital Association (AHA) Annual Survey of Hospitals, National Hospital Discharge Survey from the National Centre for Health Statistics, and Medicare Provider and Analysis Review (MedPAR) inpatient data from the Centres for Medicare and Medicaid Services strengthen the external validity of the sample $[17,18]$. It contains information included in a typical discharge summary, with safeguards in place to protect the privacy of individual patients, physicians, and hospitals.

\section{Study design}

This is a retrospective cohort study in which we queried the NIS database from the year 2007 to 2011 to identify all the hospitalisations with ECMO using ICD-9 code 39.65. We then extracted data for all hospitalisations with $\mathrm{GIH}$ from this cohort by using the appropriate ICD-9 codes (456.x, 530.x, 531.x, 532.x, 533.x, 534.x, 569.x, and 578.x). Hospitalisations for patients less than 18 years of age and those missing demographic information or admission/discharge date, in-hospital mortality status and demographics and comorbidities were excluded $[19,20]$. NIS data were merged with cost-to-charge ratio (CCR) files available from the Healthcare Cost and Utilisation Project (HCUP) to estimate cost of hospitalisations.

\section{Variables and statistical analysis}

Analyses were performed using hospital-level discharge weights provided by the NIS, to obtain national estimates of hospitalizations. The CochraneArmitage trend test was used to calculate trends in categorical variables [21]. The Wilcoxon rank sum test was used to assess continuous variables [22]. A $p$-value less than 0.05 was considered significant. Hospitalisations were also stratified by subgroups of age (18-34, 35-49, 50-64, 65-79, and > 80 years), gender, race (White, Black, Hispanic, and Others), insurance status (Medicare/Medicaid, private insurance, and self-pay/other), hospital location in different U.S. regions (Northeast, Midwest, South, and West), bed size of the hospital (small, medium, and large), and teaching status of the hospital (urban teaching, urban non-teaching, and rural). In keeping with AHRQ definitions, a hospital was considered to be a teaching hospital if it is: a) an AMA-approved residency program, b) a member of the Council of 
Table I. Baseline characteristics of patients with gastrointestinal haemorrhage $(\mathrm{GIH})$ during extracorporeal membrane oxygenation (ECMO) hospitalisations

\begin{tabular}{|c|c|c|c|c|c|c|c|}
\hline Year & 2007 & 2008 & 2009 & 2010 & 2011 & Overall & $P$-value \\
\hline Number of ECMO & 1869 & 2633 & 3166 & 3326 & 3799 & 14,793 & $<0.01$ \\
\hline Number of GIH & 40 & 83 & 105 & 147 & 283 & 659 & $<0.01$ \\
\hline$\% \mathrm{GIH}$ in ECMO & 2.1 & 3.2 & 3.3 & 4.4 & 7.5 & 4.5 & \\
\hline \multicolumn{8}{|l|}{ Age in years (\%) } \\
\hline $18-34$ & 37.1 & 11.4 & 24.6 & 14.2 & 29.5 & 23.5 & 0.41 \\
\hline $35-49$ & 11.1 & 17.3 & 19.7 & 21.5 & 11.3 & 15.7 & 0.01 \\
\hline $50-64$ & 11.3 & 5.6 & 23.6 & 21.9 & 24.7 & 20.7 & 0.01 \\
\hline $65-79$ & 0.0 & 24.2 & 9.0 & 21.8 & 11.4 & 14.3 & 0.43 \\
\hline$\geq 80$ & 0.0 & 0.0 & 0.0 & 0.0 & 1.6 & 0.7 & 0.02 \\
\hline \multicolumn{8}{|l|}{ Gender (\%) } \\
\hline Male & 67.7 & 58.9 & 47.3 & 68.2 & 52.1 & 56.7 & 0.11 \\
\hline Female & 32.3 & 41.1 & 52.7 & 31.8 & 47.9 & 43.3 & \\
\hline \multicolumn{8}{|l|}{ Race (\%) } \\
\hline White & 38.6 & 52.2 & 55.5 & 64.3 & 58.8 & 57.4 & $<0.01$ \\
\hline Black & 0.0 & 5.8 & 8.8 & 14.5 & 11.4 & 10.3 & $<0.01$ \\
\hline Hispanic & 37.1 & 17.1 & 4.6 & 10.4 & 8.5 & 11.1 & $<0.01$ \\
\hline Others & 11.6 & 18.8 & 8.7 & 3.6 & 6.9 & 8.2 & $<0.01$ \\
\hline \multicolumn{8}{|l|}{ Region (\%) } \\
\hline Northeast & 0.0 & 29.5 & 20.7 & 22.3 & 29.2 & 24.6 & $<0.01$ \\
\hline Midwest & 11.6 & 6.1 & 31.3 & 21.5 & 23.9 & 21.6 & 0.01 \\
\hline South & 54.6 & 34.6 & 22.6 & 35.7 & 39.3 & 36.2 & 0.40 \\
\hline West & 33.8 & 29.8 & 25.3 & 20.6 & 7.6 & 17.7 & $<0.01$ \\
\hline \multicolumn{8}{|l|}{ Location (\%) } \\
\hline Rural & 0.0 & 0.0 & 0.0 & 0.0 & 1.6 & 0.7 & 0.024 \\
\hline Urban nonteaching & 11.1 & 6.5 & 9.6 & 10.7 & 3.3 & 6.8 & 0.02 \\
\hline Urban teaching & 88.9 & 93.5 & 90.4 & 89.3 & 93.1 & 91.6 & 0.02 \\
\hline \multicolumn{8}{|l|}{ Median household income (\%) } \\
\hline Quartile 1 & 12.8 & 12.7 & 32.1 & 28.8 & 29.2 & 26.5 & $<0.01$ \\
\hline Quartile 2 & 24.4 & 18.0 & 37.5 & 28.9 & 21.1 & 25.3 & 0.39 \\
\hline Quartile 3 & 16.2 & 52.0 & 10.7 & 17.6 & 21.4 & 22.4 & 0.03 \\
\hline Quartile 4 & 46.6 & 17.3 & 19.7 & 21.0 & 19.8 & 21.4 & 0.07 \\
\hline \multicolumn{8}{|l|}{ Payment (\%) } \\
\hline Medicare & 0.0 & 30.0 & 18.8 & 32.3 & 16.3 & 21.0 & 0.47 \\
\hline Medicaid & 37.1 & 23.7 & 28.2 & 34.9 & 24.5 & 28.1 & 0.18 \\
\hline Private insurance & 39.0 & 40.7 & 44.3 & 25.5 & 43.9 & 39.1 & 0.37 \\
\hline Others (includes self-pay) & 23.9 & 5.6 & 8.7 & 7.3 & 15.3 & 11.8 & 0.20 \\
\hline In-hospital mortality (\%) & 56.7 & 64.1 & 61.5 & 50.8 & 61.9 & 59.3 & 0.49 \\
\hline
\end{tabular}


Shantanu Solanki, Khwaja Fahad Haq, George Jolly, Raja Chandra Chakinala, Muhammad Ali Khan, Neil R. Patel, Abhishek Bhurwal, Khwaja Saad Haq, Christopher Nabors, Sarju Ganatra, Wilbert Aronow

Table I. Cont.

\begin{tabular}{|c|c|c|c|c|c|c|c|}
\hline Year & 2007 & 2008 & 2009 & 2010 & 2011 & Overall & $P$-value \\
\hline Median length of stay (days) & 38 & 55 & 30 & 27 & 47 & $38(14-52)$ & $<0.01$ \\
\hline Cost of care (\$) & 132,420 & 205,994 & 222,869 & 222,352 & 294,728 & 215,673 & $<0.01$ \\
\hline \multicolumn{8}{|l|}{ AHRQ comorbidity measures (\%) } \\
\hline Alcohol abuse & 11.3 & 0.0 & 4.5 & 3.4 & 0.0 & 2.2 & $<0.01$ \\
\hline Deficiency anaemias & 0.0 & 18.2 & 14.5 & 17.6 & 13.3 & 14.3 & 0.25 \\
\hline Rheumatic disorders & 0.0 & 5.8 & 0.0 & 3.6 & 6.5 & 4.4 & 0.02 \\
\hline Chronic blood loss anaemia & 0.0 & 11.4 & 5.3 & 0.0 & 0.0 & 2.3 & $<0.01$ \\
\hline Congestive heart failure & 20.9 & 29.7 & 17.9 & 21.6 & 32.8 & 26.8 & 0.02 \\
\hline Chronic pulmonary disease & 0.0 & 17.2 & 8.8 & 3.7 & 9.8 & 8.6 & 0.46 \\
\hline Coagulopathy & 68.0 & 23.5 & 42.6 & 39.5 & 67.2 & 51.6 & $<0.01$ \\
\hline Depression & 0.0 & 5.8 & 0.0 & 3.6 & 8.1 & 5.1 & $<0.01$ \\
\hline Uncomplicated diabetes & 0.0 & 5.8 & 4.9 & 7.4 & 6.5 & 6.0 & 0.1 \\
\hline $\begin{array}{l}\text { Diabetes with chronic } \\
\text { complications }\end{array}$ & 0.0 & 0.0 & 0.0 & 0.0 & 1.6 & 0.7 & 0.02 \\
\hline Drug abuse & 12.8 & 0.0 & 0.0 & 0.0 & 1.6 & 1.5 & 0.01 \\
\hline Hypertension & 8.1 & 40.7 & 8.8 & 28.9 & 27.9 & 25.5 & 0.08 \\
\hline Hypothyroidism & 0.0 & 6.5 & 0.0 & 0.0 & 1.6 & 1.5 & 0.12 \\
\hline Liver disease & 25.6 & 5.6 & 0.0 & 0.0 & 6.5 & 5.1 & 0.01 \\
\hline Fluid and electrolyte disorders & 69.2 & 52.3 & 62.2 & 63.7 & 75.2 & 67.3 & $<0.01$ \\
\hline Neurological disorders & 8.1 & 12.3 & 8.9 & 13.7 & 6.9 & 9.5 & 0.15 \\
\hline Obesity & 0.0 & 0.0 & 4.4 & 3.4 & 9.8 & 5.7 & $<0.01$ \\
\hline Paralysis & 0.0 & 5.6 & 4.5 & 0.0 & 3.3 & 2.8 & 0.37 \\
\hline Peripheral vascular disorders & 12.8 & 23.5 & 18.2 & 3.7 & 6.9 & 10.4 & $<0.01$ \\
\hline Psychiatric disorder & 0.0 & 0.0 & 4.4 & 3.6 & 1.6 & 2.2 & 0.31 \\
\hline Pulmonary circulation disorders & 12.8 & 12.1 & 9.0 & 17.8 & 6.4 & 10.5 & 0.06 \\
\hline Renal failure & 23.9 & 5.9 & 13.3 & 18.3 & 17.9 & 16.1 & 0.1 \\
\hline Solid tumour without metastasis & 0.0 & 0.0 & 0.0 & 0.0 & 1.6 & 0.7 & 0.02 \\
\hline Valvular heart disease & 0.0 & 29.6 & 0.0 & 21.0 & 8.1 & 11.9 & 0.1 \\
\hline Weight loss & 0.0 & 11.5 & 33.0 & 25.5 & 36.0 & 27.9 & $<0.01$ \\
\hline
\end{tabular}

$A H R Q$ - Agency for Healthcare Research and Quality. *Variables are AHRQ comorbidity measures. 'Neurological disorders include hemiplegia, paralysis, and others. Psychiatric disorders include depression, psychosis, and others. ${ }^{\$}$ Rheumatic disorders include rheumatoid arthritis and other collagen vascular disorders.

Teaching Hospitals, or c) a hospital with a full-time intern and resident-to-bed (IRB) ratio more than 0.25 [23]. All analyses were performed using SAS 9.4 (SAS Institute Inc., Cary, North Carolina, USA).

\section{Results}

\section{Demographics and trends in hospitalisations}

Patient characteristics are summarised in Table I. The number of hospitalisations with a diagnosis code for ECMO increased progressively from 1869 in 2007 to 3799 in 2011 ( $p$ < 0.01). During the study period, 14,793 hospitalisations with ECMO were recorded. Of these, 659 hospitalisations (4.5\%) were found to have $\mathrm{GIH}$. The percentage of hospitalisations with $\mathrm{GIH}$ associated with ECMO increased from $2.1 \%$ in 2007 to $7.5 \%$ in 2011 ( $p<0.01$ ). The majority of patients were white $(57.4 \%)$ males (56.7\%) between the ages of 18 and 34 years (23.5\%). The highest rates of ECMO-related hos- 
Table II. In-hospital mortality rate in patients with GIH during ECMO hospitalisations (\%)

\begin{tabular}{|c|c|c|c|c|c|c|c|c|}
\hline Year & 2007 & 2008 & 2009 & 2010 & 2011 & Overall & Percentage change & $P$-value \\
\hline Overall & 56.7 & 64.1 & 61.5 & 50.8 & 61.9 & 59.3 & 9.2 & 0.49 \\
\hline \multicolumn{9}{|l|}{ Age in years (\%) } \\
\hline $18-34$ & 65.4 & 100.0 & 37.6 & 100.0 & 72.5 & 71.4 & 10.9 & 0.09 \\
\hline $35-49$ & 0.0 & 67.6 & 77.3 & 50.3 & 56.9 & 58.1 & 56.9 & 0.01 \\
\hline $50-64$ & 0.0 & 100.0 & 100.0 & 67.4 & 65.6 & 71.3 & 65.6 & $<0.01$ \\
\hline $65-79$ & 0.0 & 75.6 & 50.0 & 50.6 & 71.1 & 62.9 & 71.1 & 0.22 \\
\hline$\geq 80$ & 0.0 & 0.0 & 0.0 & 0.0 & 100.0 & 100 & 100.0 & 0.04 \\
\hline \multicolumn{9}{|l|}{ Gender (\%) } \\
\hline Male & 48.0 & 69.4 & 71.6 & 53.5 & 65.7 & 62.4 & 36.9 & 0.01 \\
\hline Female & 75.0 & 56.6 & 52.5 & 45.2 & 57.8 & 55.3 & -22.9 & 0.03 \\
\hline \multicolumn{9}{|l|}{ Race (\%) } \\
\hline White & 21.0 & 66.6 & 54.6 & 45.1 & 55.2 & 52.5 & 163.1 & $<0.01$ \\
\hline Black & 0.0 & 100.0 & 50.6 & 76.3 & 71.2 & 72.1 & 71.2 & 0.01 \\
\hline Hispanic & 65.4 & 100.0 & 100.0 & 33.0 & 76.6 & 71.3 & 17.0 & 0.02 \\
\hline Others & 100.0 & 34.4 & 100.0 & 100.0 & 100.0 & 81.0 & 0.0 & * \\
\hline \multicolumn{9}{|l|}{ Region (\%) } \\
\hline Northeast & 0.0 & 60.0 & 100.0 & 83.3 & 55.6 & 67.9 & 55.6 & $<0.01$ \\
\hline Midwest & 100.0 & 0.0 & 57.2 & 16.4 & 80.0 & 58.3 & -20.0 & 0.39 \\
\hline South & 61.7 & 83.7 & 57.9 & 61.3 & 62.5 & 64.3 & 1.3 & 0.03 \\
\hline West & 33.8 & 58.6 & 38.6 & 33.5 & 26.3 & 38.7 & -22.3 & $<0.01$ \\
\hline \multicolumn{9}{|l|}{ Location (\%) } \\
\hline Rural & 0.0 & 0.0 & 0.0 & 0.0 & 100.0 & 100.0 & 100.0 & 0.04 \\
\hline Urban nonteaching & 0.0 & 100.0 & 46.6 & 0.0 & 0.0 & 22.5 & * & $<0.01$ \\
\hline Urban teaching & 63.8 & 61.6 & 63.1 & 56.9 & 62.6 & 61.4 & -1.8 & $<0.01$ \\
\hline \multicolumn{9}{|l|}{ Median household income (\%) } \\
\hline Quartile 1 & 0.0 & 0.0 & 42.4 & 63.1 & 61.1 & 52.5 & 61.1 & 0.04 \\
\hline Quartile 2 & 100.0 & 100.0 & 73.8 & 37.6 & 38.3 & 55.7 & -61.7 & 0.22 \\
\hline Quartile 3 & 50.0 & 55.3 & 50.3 & 61.4 & 75.6 & 64.1 & 51.3 & 0.05 \\
\hline Quartile 4 & 52.0 & 100.0 & 75.2 & 34.7 & 65.3 & 61.9 & 25.7 & 0.16 \\
\hline \multicolumn{9}{|l|}{ Payment (\%) } \\
\hline Medicare & 0.0 & 80.3 & 76.2 & 34.1 & 79.8 & 63.7 & 79.8 & 0.12 \\
\hline Medicaid & 65.4 & 47.5 & 49.0 & 40.8 & 32.6 & 41.7 & -50.1 & $<0.01$ \\
\hline Private insurance & 50.3 & 56.8 & 55.7 & 86.2 & 70.4 & 67.0 & 39.8 & $<0.01$ \\
\hline Others (includes self-pay) & 53.6 & 100.0 & 100.0 & 49.8 & 65.7 & 68.1 & 22.5 & 0.05 \\
\hline
\end{tabular}

${ }^{\star}$ Cannot be calculated.

pitalisations were observed in the southern region $(36.2 \%)$, and the lowest number were seen in western region (17.7\%). The vast majority of the hospitalisations were seen in urban teaching hospitals (91.6\%). Hospitalisations with GIH associated with ECMO progressively increased in urban 
teaching hospitals from $88.9 \%$ in 2007 to $93.1 \%$ in 2011 ( $p<0.01)$, and those in urban non-teaching decreased from $11.1 \%$ in 2007 to $3.3 \%$ in 2011 ( $p<0.01$ ). Private insurance paid for $39.1 \%$ and Medicaid paid for $28.1 \%$ of the total hospitalisations studied.

\section{Length of stay and cost of care}

Median length of stay (LOS) was 38 days (interquartile range 14 to 52 days). The mean cost of care for hospitalisation with GIB associated with ECMO increased significantly from $\$ 132,420$ in 2007 to $\$ 294,728$ in 2011 ( $p<0.01)$.

\section{All-cause inpatient mortality}

The overall in-hospital all-cause mortality as sociated with GIH in ECMO hospitalisations was 59.3\% (Table II). There was an insignificant rise from $56.7 \%$ in 2007 to $61.9 \%$ in 2011 ( $p=0.49$ ). The mortality rate was highest in the age group over 80 years (100\%) and lowest in the 35- 49-yearold age group (58.1\%). The mortality rate was lowest for whites (52.5\%); however, the percentage increase in the white population was highest between 2007 and 2011 (163\%). It was higher in males (62.4\%) and blacks (72.1\%).

\section{AHRQ co-morbidities}

As per our analysis, the most frequent coexisting conditions coded with these hospitalisations were renal failure (70.9\%), anaemia (54.5\%), and congestive heart failure (26.8\%). Several other comorbidities were also associated, as seen in Table I.

\section{Discussion}

Extracorporeal membrane oxygenation use has been increasing over the past years. Fenton et al. found that unweighted ECMO discharges increased from 352 in 2002 to 2715 in 2012 [1]. Our analysis shows an increase in ECMO-related hospitalisations from 1869 in 2007 to 3799 in 2011 ( $p$ < 0.01). ECMO use is associated with multiple complications, of which bleeding and thrombosis are the major determinants of mortality [11, 13, 24-28]. We identified an increasing proportion of hospitalisations for ECMO which were associated with coagulopathy and $\mathrm{GIH}$.

In earlier reports, GIH was noted in less than $10 \%$ of patients [29-31]. In a retrospective cohort study conducted by Mazzeffi et al. 18 out of 132 recruited ECMO patients (13.6\%) had GIB [5]. In a similar study conducted at Westchester Medical Centre in patients with VA ECMO and concomitant IABP implantation, 21 out of 135 patients developed GIB (15.6\%) [32]. These numbers are higher, compared to the rate noted in our study (4.5\%).
This may be a result of possible differences in the characteristics of the cohorts studied, comorbid conditions, sample size, and coding inaccuracies.

Sepsis, multi-organ failure, and imbalance between pro-coagulant and anticoagulant pathways cause platelet activation and consumption of clotting factors, leading to an acquired state of clotting factor deficiency [33-35]. Contact between blood and non-endothelial surface activates the coagulation pathway leading to thrombosis and subsequent bleeding [34]. Utilisation of large bore arterial and venous access also lead to bleeding complications [34]. Because heparin is widely used for anticoagulation in these patients, heparin-induced thrombocytopaenia (HIT) may also be a major factor responsible for bleeding. GIB in ECMO patients is also attributed to arterio-venous malformation (AVM), which is stimulated by tissue hypoperfusion caused by non-pulsatile flow $[36,37]$. These factors play an important role in promoting $\mathrm{GIH}$ in patients undergoing ECMO, while other factors not yet identified may contribute to GIH as well.

Mazzeffi et al. achieved limited success in preventing GIH in ECMO patients with the use of prophylactic measures such as proton pump inhibitor (PPI) therapy [14]. In many cases, despite investigation by upper and lower endoscopy and tagged red blood cell (RBC) scans, no discrete bleeding source is identified in these patients [14]. However, it is crucial to note that the sample size of this study was small. In largescale multi-centre trials, PPIs might show better outcomes.

Throughout our study period, in-hospital mortality was more than $50 \%$, which has not changed significantly in the last few years. With the increasing use of newer interventions, especially membrane oxygenators, bleeding and thrombotic complication associated with ECMO use may be reduced [38]. VV ECMO use in select patients rather than VA ECMO could also reduce incidence of GI haemorrhage and haemolysis, leading to better survival and lesser complications [30].

Our results also demonstrated higher overall mortality rates among black males. A similar finding was made in a single-centre study of patients who had received VV ECMO $(n=41)$, in which members of minority groups $(n=11)$ had increased mortality at 30 days and 1 year post ECMO [32]. Race was noted to be an independent predictor for survival at 30 days, although this was no longer statistically significant after adjustment for shock and lung transplant status. Limited data are available to compare hospitalisations by geographic region. In the present study, we found that ECMO hospitalisations in the south were most common and were least common in the west. In the past 2 years, there has been an increasing 
trend toward hospitalisations in the northeast and mid-west. According to a study in Norway, more than $90 \%$ of all ECMO therapy was performed in urban teaching hospitals, while only around $2 \%$ was performed in rural hospitals [39]. In our study, close to $92 \%$ of all the hospitalisations were seen in urban teaching hospitals. We observed a $62.8 \%$ increase in the average cost for hospitalisation for GIB associated with ECMO use. Such a trend was previously noted in an earlier analysis by Maxwell et al., which found that for ECMO hospitalisations between 1998 and 2009, there was an increase in hospital costs and worse outcomes, in large measure related to use of ECMO in non-cardiotomy patients [40]. The present results are consistent with this trend and also may relate to increasing complexity of care and use of ECMO among patients with more serious medical comorbidities.

This study identifies gastrointestinal bleeding as a major complication in patients receiving ECMO therapy, which puts considerable economic burden on the healthcare system. Our study results have important implications because they are applicable to the patients receiving acute interventional care for life-threatening clinical conditions in hospitals all over the U.S. The causes and mechanisms leading to GIB in these patients are not yet fully understood. In the future, animal models might help us understand the exact pathophysiological basis of gastrointestinal bleeding in these patients. Randomised clinical trials (RCTs) comparing ECMO with conventional therapies might identify the risk factors associated with GIB in ECMO patients. For now, we believe that stringent protocols for initiation and maintenance of anti-coagulation in ECMO patients can reduce the incidence of GIB. We also believe that PPIs remain crucial in preventing upper GIB in these patients.

This study has several limitations. Firstly, the NIS does not contain data related to certain aspects of clinical management. Variability in the use and impact of modalities employed to mitigate against bleeding could therefore not be accounted for in this study. Because of the lack of specificity in codes identifying $\mathrm{GIH}$, the particular aetiology of haemorrhage could also not be determined. Furthermore, this analysis could not account for the duration of ECMO, which has a direct association with bleeding complications [41]. It also could not ascertain whether VV or VA ECMO was utilised and how that may have influenced the outcomes.

To conclude, there was a significant increase in ECMO hospitalisations with gastrointestinal bleeding during our study period. Also, the inpatient mortality rate and cost of care increased significantly in ECMO hospitalisations with gastrointestinal bleeding during the study period.

\section{Conflict of interest}

The authors declare no conflict of interest.

\section{References}

1. Mosier JM, Kelsey M, Raz Y, et al. Extracorporeal membrane oxygenation (ECMO) for critically ill adults in the emergency department: history, current applications, and future directions. Crit Care 2015; 19: 431.

2. Makhoul M, Bitton-Worms K, Adler Z, Saeed A, Cohen O, Bolotin G. Extracorporeal membrane oxygenation (ECMO) - a lifesaving technology. Review and single-center experience. Rambam Maimonides Med J 2019; 10: e0013.

3. Chowdhury O, Greenough A. Neonatal ventilatory techniques - which are best for infants born at term? Arch Med Sci 2011; 7: 381-7.

4. Gaffney AM, Wildhirt SM, Griffin MJ, Annich GM, Radomski MW. Extracorporeal life support. BMJ 2010; 341: c5317.

5. Brechot N, Luyt CE, Schmidt M, et al. Venoarterial extracorporeal membrane oxygenation support for refractory cardiovascular dysfunction during severe bacterial septic shock. Crit Care Med 2013; 41: 1616-26.

6. Park TK, Yang JH, Jeon K, et al. Extracorporeal membrane oxygenation for refractory septic shock in adults. Eur J Cardiothorac Surg 2015; 47: e68-74.

7. Ried M, Bein T, Philipp A, et al. Extracorporeal lung support in trauma patients with severe chest injury and acute lung failure: a 10-year institutional experience. Crit Care 2013; 17: R110.

8. Tariq S, Garg A, Gass A, Aronow WS. Myocarditis due to systemic lupus erythematosus associated with cardiogenic shock. Arch Med Sci 2018; 14: 460-2.

9. Makdisi G, Wang IW. Extra Corporeal Membrane Oxygenation (ECMO) review of a lifesaving technology. J Thorac Dis 2015; 7: E166-76.

10. Extracorporeal Life Support Organization (ELSO). ECLS Registry Report. 2019. Available from: https://www. elso.org/Registry/Statistics/InternationalSummary.aspx (Accessed: 18.08.2019).

11. Zangrillo A, Landoni G, Biondi-Zoccai G, et al. A metaanalysis of complications and mortality of extracorporeal membrane oxygenation. Crit Care Resusc 2013; 15: 172-8.

12. Hemmila MR, Rowe SA, Boules TN, et al. Extracorporeal life support for severe acute respiratory distress syndrome in adults. Ann Surg 2004; 240: 595-605; discussion 605-7.

13. Liao X, Li B, Cheng Z. Extracorporeal membrane oxygenation in adult patients with acute fulminant myocarditis: clinical outcomes and risk factor analysis. Herz 2018; 43: 728-32.

14. Mazzeffi M, Kiefer J, Greenwood J, et al. Epidemiology of gastrointestinal bleeding in adult patients on extracorporeal life support. Intensive Care Med 2015; 41: 2015.

15. Slottosch I, Liakopoulos O, Kuhn E, et al. Outcomes after peripheral extracorporeal membrane oxygenation therapy for postcardiotomy cardiogenic shock: a single-center experience. J Surg Res 2013; 181: e47-55.

16. Healthcare Cost and Utilization Project. Overview of the National (Nationwide) Inpatient Sample (NIS). Available from: https://www.hcup-us.ahrq.gov/nisoverview. jsp (Accessed: 17.01.2018).

17. Healthcare Cost and Utilization Project. NIS Related Reports. Available from: https://www.hcup-us.ahrq.gov/db/ nation/nis/nisrelatedreports.jsp (Accessed 17.01.2018). 
18. Badheka AO, Chothani A, Mehta K, et al. Utilization and adverse outcomes of percutaneous left atrial appendage closure for stroke prevention in atrial fibrillation in the United States: influence of hospital volume. Circ Arrhythm Electrophysiol 2015; 8: 42-8.

19. Patel NJ, Deshmukh A, Pant S, et al. Contemporary trends of hospitalization for atrial fibrillation in the United States, 2000 through 2010: implications for healthcare planning. Circulation 2014; 129: 2371-9.

20. Deshmukh A, Patel NJ, Pant S, et al. In-hospital complications associated with catheter ablation of atrial fibrillation in the United States between 2000 and 2010: analysis of 93801 procedures. Circulation 2013; 128: 2104-12.

21. Armitage P. Tests for linear trends in proportions and frequencies. Biometrics 1955; 11: 375-86.

22. Nahm FS. Nonparametric statistical tests for the continuous data: the basic concept and the practical use. Korean J Anesthesiol 2016; 69: 8-14.

23. Healthcare Cost and Utilization Project. HCUP Methods Series. Available from: https://www.hcup-us.ahrq.gov/ reports/methods/1998ChangesintheNISRedesignFinal. pdf. (Accessed: 17.01.2018).

24. Dalton HJ, Reeder R, Garcia-Filion P, et al. Factors associated with bleeding and thrombosis in children receiving extracorporeal membrane oxygenation. Am J Respir Crit Care Med 2017; 196: 762-71.

25. Khorsandi M, Dougherty S, Bouamra O, et al. Extra-corporeal membrane oxygenation for refractory cardiogenic shock after adult cardiac surgery: a systematic review and meta-analysis. J Cardiothorac Surg 2017; 12: 55.

26. Mazzeffi M, Greenwood J, Tanaka K, et al. Bleeding, transfusion, and mortality on extracorporeal life support: ECLS Working Group on Thrombosis and Hemostasis. Ann Thorac Surg 2016; 101: 682-9.

27. Oliver WC. Anticoagulation and coagulation management for ECMO. Semin Cardiothorac Vasc Anesth 2009 13: 154-75.

28. Paden ML, Conrad SA, Rycus PT, Thiagarajan RR, ELSO Registry. Extracorporeal Life Support Organization registry report 2012. ASAIO J 2013; 59: 202-10.

29. Chang $\mathrm{CH}$, Chen HC, Caffrey JL, et al. Survival analysis after extracorporeal membrane oxygenation in critically ill adults: a nationwide cohort study. Circulation 2016; 133: 2423-33.

30. Kon ZN, Bittle GJ, Pasrija C, et al. Venovenous versus venoarterial extracorporeal membrane oxygenation for adult patients with acute respiratory distress syndrome requiring precannulation hemodynamic support: a review of the ELSO registry. Ann Thorac Surg 2017; 104: 645-9.

31. Smith A, Hardison D, Bridges B, Pietsch J. Red blood cell transfusion volume and mortality among patients receiving extracorporeal membrane oxygenation. Perfusion 2013; 28: 54-60.

32. Gass A, Palaniswamy C, Aronow WS, et al. Peripheral venoarterial extracorporeal membrane oxygenation in combination with intra-aortic balloon counterpulsation in patients with cardiovascular compromise. Cardiology 2014; 129: 137-43.

33. Heilmann C, Geisen U, Beyersdorf F, et al. Acquired von Willebrand syndrome in patients with extracorporeal life support (ECLS). Intensive Care Med 2012; 38: 62-8.

34. Murphy DA, Hockings LE, Andrews RK, et al. Extracorporeal membrane oxygenation-hemostatic complications. Transfus Med Rev 2015; 29: 90-101.

35. Patroniti N, Scaravilli V. Hemostatic changes during extracorporeal membrane oxygenation: a commentary. Ann Transl Med 2016; 4: 140.
36. Koning NJ, Vonk AB, van Barneveld LJ, et al. Pulsatile flow during cardiopulmonary bypass preserves postoperative microcirculatory perfusion irrespective of systemic hemodynamics. J Appl Physiol (1985) 2012; 112: 1727-34.

37. Sarosiek K, Hirose H, Pitcher HT, Cavarocchi NC. Adult extracorporeal membrane oxygenation and gastrointestinal bleeding from small bowel arteriovenous malformations: a novel treatment using spiral enteroscopy. J Thorac Cardiovasc Surg 2012; 143: 1221-2.

38. Khoshbin E, Roberts N, Harvey C, et al. Poly-methyl pentene oxygenators have improved gas exchange capability and reduced transfusion requirements in adult extracorporeal membrane oxygenation. ASAIO J 2005; 51: 281-7.

39. Mishra V, Svennevig JL, Bugge JF, et al. Cost of extracorporeal membrane oxygenation: evidence from the Rikshospitalet University Hospital, Oslo, Norway. Eur J Cardiothorac Surg 2010; 37: 339-42.

40. Maxwell BG, Powers AJ, Sheikh AY, Lee PH, Lobato RL, Wong JK. Resource use trends in extracorporeal membrane oxygenation in adults: an analysis of the Nationwide Inpatient Sample 1998-2009. J Thorac Cardiovasc Surg 2014; 148: 416-21.e411.

41. Omar HR, Mirsaeidi M, Mangar D, Camporesi EM. Duration of ECMO Is an Independent Predictor of Intracranial Hemorrhage Occurring During ECMO Support. ASAIO J 2016; 62: 634-6. 